\title{
PROPOSTA DE CALÇADAS ACESSÍVEIS EM CONSONÂNCIA COM A ARBORIZAÇÃO VIÁRIA ESTABELECIDA EM ITANHAÉM - SP
}

\author{
PROPOSAL OF ACCESSIBLE SIDEWALK IN CONSIDERATION OF \\ AFFORESTATION ROAD ESTABLISHED IN ITANHAÉM - SP
}

\author{
Tamara Ribeiro Botelho de Carvalho Maria ${ }^{1}$, Daniela Biondi², Kendra Zamproni ${ }^{3}$
}

\begin{abstract}
RESUMO
O crescimento urbano não planejado é uma questão recorrente e pode trazer inúmeros problemas de cunho social e ambiental. A utilização de calçadas verdes acessíveis surge como forma de mitigar algumas destas dificuldades, democratizando as calçadas para atender todas as pessoas, inclusive as com mobilidade reduzida e considerando a vegetação como forma de melhoria da qualidade ambiental. O objetivo deste trabalho foi avaliar a estrutura física e da vegetação existente nas calçadas de Itanhaém - SP, visando a aplicabilidade das calçadas verdes acessíveis. A coleta dos dados foi realizada por amostragem estratificada. Foram mensurados a largura de calçada, posição da árvore na calçada, sua altura total e de bifurcação do tronco. A proposição para as calçadas verdes acessíveis foi baseada na lei Federal 10.098/2000, na ABNT NBR 9050 e na cartilha de calçadas acessíveis no Estado de São Paulo. A largura média de calçadas de Itanhaém foi de 2,87 m. A aplicação da faixa de circulação livre com largura igual ou superior à mínima recomendável é possível em $61 \%$ das calçadas. A altura de bifurcação foi menor que $1,8 \mathrm{~m}$ em $76,8 \%$ da arborização, demonstrando que há necessidade de podas de manutenção e produção de mudas adequadas à arborização viária.
\end{abstract}

Palavras-chave: Arborização urbana; Acessibilidade em calçadas; Cidades acessíveis.

\begin{abstract}
Unplanned urban growth is a recurring issue and can bring numerous social and environmental problems. The use of accessible green sidewalks appears as a way to mitigate some of these difficulties, democratizing the sidewalks to attend all people, including those with reduced mobility and considering the vegetation as a way of improving the environmental quality. The objective of this work was to evaluate the physical structure and the vegetation existing in the sidewalks of Itanhaém - SP, aiming at the applicability of accessible green sidewalks. Data were collected by stratified sampling. The width of the sidewalk, the position of the tree on the sidewalk, its total height and the bifurcation of the trunk were measured. The proposal for accessible green sidewalks was based on Federal Law 10.098 / 2000, ABNT NBR 9050 and the accessible sidewalk booklet in the State of São Paulo. The average width of Itanhaém sidewalks was $2.87 \mathrm{~m}$. The application of the free circulation range with a width equal to or greater than the recommended minimum is possible in $61 \%$ of the sidewalks. The bifurcation height was lower than $1.8 \mathrm{~m}$ in $76.8 \%$ of the trees, demonstrating that there is a need for maintenance pruning and seedling production adequate for tree planting.
\end{abstract}

Keywords: Urban forestry; Accessibility of sidewalks; Accessible cities.

\footnotetext{
Recebido em 20.10.2017 e aceito em 15.01.2018

1 Engenheira Florestal, Me. Engenharia Florestal, Doutoranda do Programa de pós-graduação em Engenharia Florestal da Universidade Federal do Paraná.Curitiba/PR. E-mail: trbotelhomaria@gmail.com

2 Engenheira Florestal, Prof ${ }^{-}{ }^{a} \stackrel{a}{ }$ da Universidade Federal do Paraná. Curitiba/PR. E-mail: dbiondi@ufpr.br

3 Engenheira Florestal, Me. Engenharia Florestal. Curitiba/PR. E-mail: kendra.zam@gmail.com
} 


\section{INTRODUÇÃO}

O aumento da densidade populacional nos centros urbanos tem despertado inúmeras discussões relacionadas à qualidade de vida na área urbana (GRISE; BIONDI; ARAKI, 2016). É nítido que o processo de urbanização gerou e ainda gera impactos ambientais e sociais, mas que podem ser minimizados e até evitados mediante um planejamento urbano eficaz (UGEDA JUNIOR, 2014).

Assim como outras formas da infraestrutura das cidades, as árvores fornecem uma variedade de serviços e valores às comunidades, dentre eles a melhoria da qualidade do ar, diminuição do uso de energia elétrica, benefícios à saúde, habitat para aves e outros animais, recreação e estética (ZHU; ZHANG, 2008).

A maximização da qualidade de vida, a acessibilidade e a mobilidade urbana configuram-se como indicadores da inclusão social, o que evidencia que tais componentes são indispensáveis à toda população urbana (LICHT, 2015). Soares, Alves e Targino (2017) corroboram com o exposto e afirmam que a arborização planejada previamente, é fundamental para que a locomoção dos pedestres não seja interferida pelo uso incorreto do solo.

A necessidade de construir espaços menos hostis nas áreas urbanas abre caminho para os estudos da vegetação e sua compatibilidade com as calçadas, de modo a propiciar melhor qualidade de vida e melhorar as condições de oportunidades de acesso a todos os cidadãos (LIMA NETO et al., 2010).

Considerando que as cidades deveriam ser planejadas primordialmente para as pessoas, a acessibilidade e mobilidade são questões de extrema importância para que toda a população, levando em conta que crianças, jovens, adultos idosos e pessoas com deficiência ou mobilidade reduzida, consigam utilizá-las (LAMOUNIER, 2015).

De maneira genérica, Pereira, Barbosa e Pereira Júnior (2016) definem a acessibilidade como um conjunto de medidas urbanísticas e sociais, que tem por finalidade inserir de maneira igualitária, pessoas com características limitantes, à sociedade.

Ribeiro e Varela (2015) afirmam que a segurança na livre circulação da população com deficiência é um direito legal e não mera sensibilização. Biondi e Lima Neto (2011) afirmam ainda que a acessibilidade pode ser definida como exercício de cidadania, onde todos os indivíduos que têm seus direitos assegurados por lei devem ser respeitados.

Os problemas de impedimento no espaço urbano, relacionados às limitações de mobilidade e o livre acesso de pessoas a determinados ambientes, desrespeitam as necessidades de parte da população incapacitando o meio de fornecer acesso à todos (RUOSO, 2012; HAUBRICHT; FIORINI, 2014; SOARES; ALVES; TARGINO, 2016). 
Para tornar o espaço público acessível, é necessário eliminar obstáculos nos equipamentos e mobiliários urbanos, que impedem ou dificultam a locomoção das pessoas ao longo das calçadas (KEPPE JUNIOR, 2008).

Considera-se para o desenho universal das calçadas acessíveis a utilização de três faixas de utilização: faixa de circulação livre, faixa de serviços e faixa de acesso; para áreas residenciais, as calçadas devem atender à largura mínima aceitável de 2,0 m, considerando a obrigatoriedade das faixas de circulação livre e de serviços; já para áreas comerciais é necessário que as calçadas atendam a largura mínima aceitável de 2,7 m, considerando a obrigatoriedade das faixas de circulação livre, de serviços e acesso (KEPPE JUNIOR, 2008).

Para a promoção da acessibilidade é necessário que as calçadas sigam um padrão de construção que seja compatível com a incorporação dos equipamentos urbanos (árvores, postes, placas de sinalização, entre outros) para que estes não se tornem um impedimento (BIONDI; LIMA NETO, 2011).

Soares, Alves e Targino (2017) citam também que um planejar previamente da arborização permite que ocorra o adequado uso do solo sem interferir na locomoção de pedestres, condicionando a acessibilidade urbana.

Diante do exposto, o presente trabalho teve por objetivo avaliar as condições atuais das calçadas de Itanhaém - SP, visando o planejamento adequado para a inserção de calçadas ecológicas, que conciliem a acessibilidade e a arborização existente no município.

\section{MATERIAL E MÉTODOS}

A presente pesquisa foi desenvolvida no município de Itanhaém, litoral sul do Estado de São Paulo (Figura 1), sob as coordenadas 2411"1' Sul e 4647"22' Oeste, tendo como limite os municípios de São Vicente, Mongaguá, Pedro de Toledo, Peruíbe, Juquitiba, São Bernardo do Campo e São Paulo (IPT, 2012).

O município conta com 94.000 habitantes, e apresenta área territorial de 601,67 km², com $99 \%$ da população localizada na área urbanizada do município $\left(40,8 \mathrm{~km}^{2}\right)$, sendo dividido em 15 grandes regionais (IBGE, 2015).

Segundo a classificação de Alvarez et. al (2013) o clima predominante no município é do tipo Af, caracterizado como clima tropical sem estação seca, com precipitação média mensal maior que $60 \mathrm{~mm}$, e a temperatura média do mês mais frio de $18^{\circ} \mathrm{C}$.

Para a quantificação das vias urbanizadas, e contagem dos indivíduos arbóreos, foi percorrido de carro todo o município, contabilizando as vias urbanizadas (com leito carroçável pavimentado, calçadas e guias) que posteriormente foram plotadas no software Google Earth® 
e calculada a quilometragem linear de vias urbanizadas e o número de árvores de cada regional.

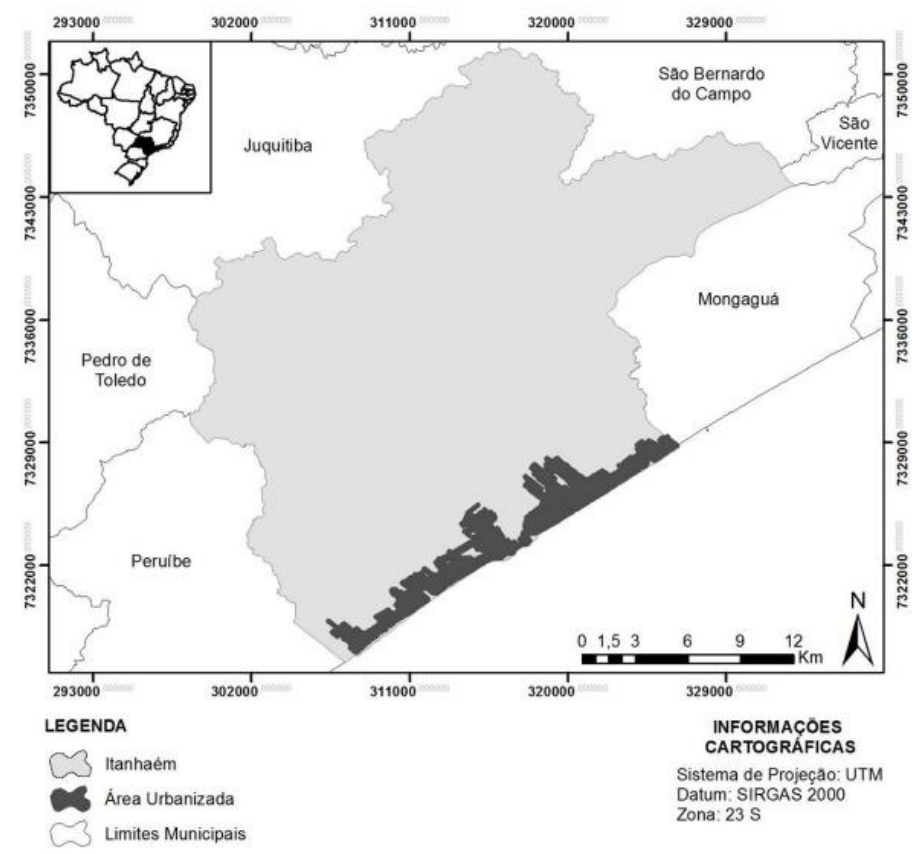

Figura 1. Localização do município de Itanhaém - SP

Figure 1. Location of the municipality of Itanhaém - SP

Para a caracterização da estrutura física foi realizado um inventário qualitativo, onde utilizou-se o processo de amostragem estratificada, sendo utilizada a divisão administrativa do município em 15 regionais para a definição dos estratos (Figura 2).

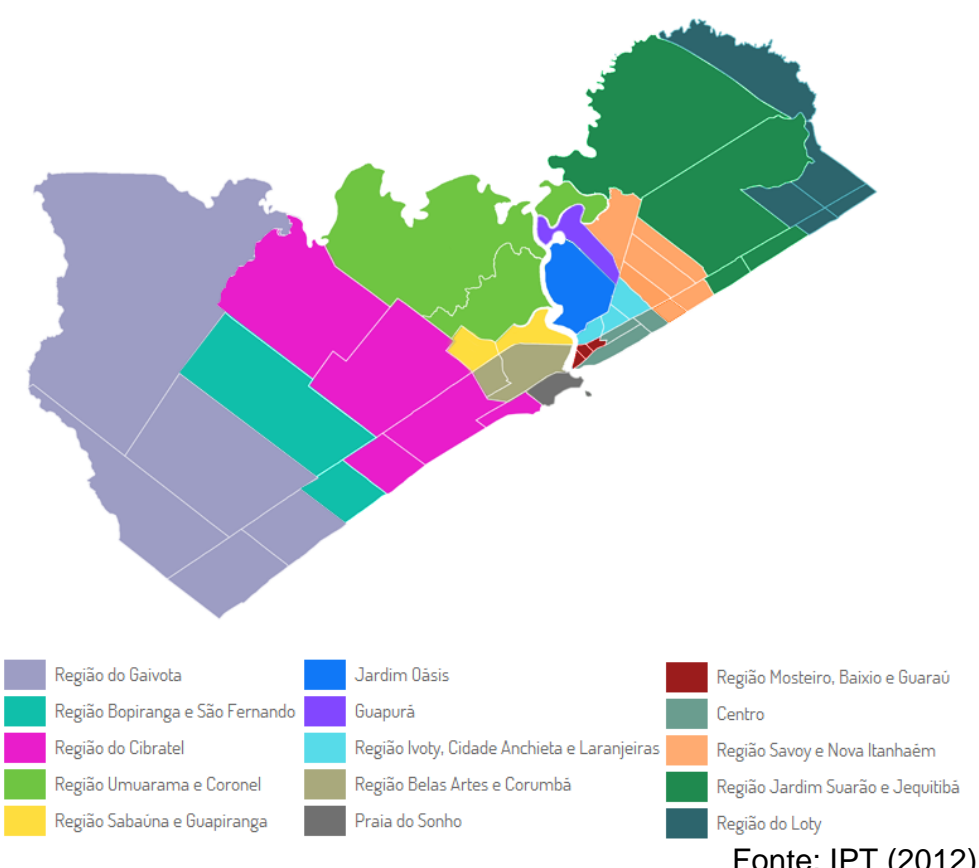

Figura 2. Subdivisões das regionais do município de Itanhaém - SP

Figure 2. Subdivisions of the regional of Itanhaém - SP 
A forma da unidade amostral foi linear, com comprimento médio de $100 \mathrm{~m}$ ou variando de 70 a 120 m, de acordo com a característica de cada regional, de modo que o comprimento caracterizasse a melhor distribuição de parcelas. As parcelas potenciais de cada regional foram numeradas e sorteadas aleatoriamente.

Para a análise qualitativa das calçadas e das árvores foram avaliados: largura de calçada, distância do meio fio à árvore, distância do limite de terreno/casa até a árvore, altura total da árvore e altura de bifurcação do tronco, diâmetro à altura do peito (DAP), área livre de canteiro e condições físicas das raizes.

A altura da árvore foi aferida com o uso de hipsômetro, bem como a altura da primeira bifurcação. As variáveis de circunferência à altura do peito, área livre do canteiro, largura de calçada, distâncias da árvore à calçada e ao meio fio foram aferidas com uso de trena métrica.

As condições físicas do sistema radicular das árvores foram avaliados em escala. Para a avaliação do sistema radicular a escala variou entre profunda (não aflora na superfície), pouco superficial (raiz aflora para superfície, mas não causa danos à calçada ou saliências que atrapalhem a circulação de pessoas) e superficial (raiz aflora na superfície dificultando a circulação de pessoas e destruindo as calçadas).

A comparação das calçadas atuais com o ideal de calçadas acessíveis levou em consideração a metodologia proposta no plano municipal de acessibilidade do Governo do Estado de São Paulo, a lei Federal no 10.098/00 que dispõe sobre critérios básicos para a promoção da acessibilidade das pessoas com deficiência ou com mobilidade reduzida e a ABNT NBR 9050 que dispõe sobre acessibilidade a espaços e equipamentos urbanos (LAMOUNIER, 2015).

Para o planejamento das calçadas acessíveis foram levadas em consideração as faixas de circulação livre, de serviços e de acesso, com suas funções e dimensões (Tabela 1).

Tabela 1. Classificação das faixas de circulação livre, de serviço e de acesso Table 1. Classification of free circulation, service and access ranges

\begin{tabular}{|c|c|c|}
\hline FAIXA & DESCRIÇÃO DAS FUNÇÕES & LARGURA \\
\hline $\begin{array}{l}\text { Circulação } \\
\quad \text { livre }\end{array}$ & $\begin{array}{l}\text { Área do passeio ou calçada destinada exclusivamente à circulação de } \\
\text { pedestres }\end{array}$ & $\begin{array}{l}\text { 1,20 m (mínima } \\
\text { aceitável) } \\
\text { 1,50 m (mínima } \\
\text { recomendável) }\end{array}$ \\
\hline Serviços & $\begin{array}{c}\text { Destinada à colocação de árvores, rampas de acesso para veículos ou pessoas } \\
\text { com deficiência, poste de iluminação, sinalização de trânsito e mobiliário } \\
\text { urbano como bancos, floreiras, telefones, caixa de correio e lixeiras }\end{array}$ & $>0,8 \mathrm{~m}$ \\
\hline Acesso & $\begin{array}{l}\text { Área em frente a imóvel ou terreno, onde pode estar a vegetação, rampas, } \\
\text { toldos, propaganda e mobiliário móvel como mesas de bar e floreiras, desde } \\
\text { que não impeçam o acesso aos imóveis. É, portanto, uma faixa de apoio a } \\
\text { propriedade }\end{array}$ & $>0,7 \mathrm{~m}$ \\
\hline
\end{tabular}


Posteriormente, foram sugeridas as possíveis divisões já existentes em faixas nas calçadas, levando em consideração as características da urbanização e da arborização de cada regional.

\section{RESULTADOS E DISCUSSÃO}

As vias urbanizadas no município de Itanhaém - SP somam 421,56 km, totalizando 843,12 km de calçadas, e 18.128 árvores em vias urbanas (Tabela 2). A regional Guapurá não foi avaliada, pois durante a pesquisa, a mesma passava por obras de estruturação, e não apresentava vegetação estabelecida.

A regional Guapiranga e Sabaúna foi a que apresentou menor índice de árvores por quilômetro, com 14,9 árvores por quilômetros de ruas, enquanto a regional Loty apresentou o maior índice, com 89 árvores por quilômetro de ruas.

Tabela 1. Caracterização da urbanização e arborização das calçadas de Itanhaém-SP

Table 1. Characterization of urbanization and afforestation of sidewalks of Itanhaém-SP

\begin{tabular}{lllllllll}
\hline Regional & VU (KM) & Narv & $\begin{array}{l}\text { Narv/ } \\
\text { Km }\end{array}$ & $\begin{array}{l}\text { LC } \\
(\mathbf{m})\end{array}$ & $\begin{array}{l}\text { ALC } \\
(\mathbf{m})\end{array}$ & $\begin{array}{l}\text { Harv } \\
(\mathbf{m})\end{array}$ & $\begin{array}{l}\text { H bif } \\
(\mathbf{m})\end{array}$ & $\begin{array}{l}\text { DAP } \\
(\mathbf{c m})\end{array}$ \\
\hline Belas Artes e Corumbá & 32 & 912 & 28,5 & 2,80 & 0,44 & 3,71 & 0,80 & 10,17 \\
Bopiranga & 28,39 & 1963 & 69,1 & 3,14 & 3,52 & 4,08 & 0,88 & 13,46 \\
Centro & 23,24 & 1011 & 43,5 & 2,97 & 2,27 & 5,40 & 1,32 & 17,38 \\
Cibratel & 77,64 & 3914 & 50,4 & 3,03 & 1,73 & 4,80 & 2,31 & 17,19 \\
Gaivota & 49,43 & 2366 & 47,9 & 2,97 & 1,02 & 4,14 & 0,57 & 12,88 \\
Guapiranga e Sabaúna & 15,92 & 237 & 14,9 & 2,71 & 2,98 & 4,44 & 0,79 & 17,48 \\
Ivoty & 20,22 & 456 & 22,6 & 2,86 & 0,49 & 4,07 & 0,92 & 14,69 \\
Loty & 27,5 & 2473 & 89,9 & 3,46 & 2,75 & 4,44 & 1,01 & 14,82 \\
Mosteiro & 5,79 & 90 & 15,5 & 2,63 & 0,2 & 4,79 & 1,37 & 21,18 \\
Praia dos Sonhos & 11,89 & 303 & 25,5 & 1,98 & 0,5 & 5,26 & 0,84 & 17,40 \\
Savoy e Nova Itanhaém & 81,71 & 1777 & 21,7 & 2,69 & 1,5 & 4,22 & 0,90 & 17,15 \\
Suarão & 34,75 & 2018 & 58,1 & 2,41 & 1,56 & 4,51 & 1,46 & 22,81 \\
Umuarama & 6,48 & 443 & 68,4 & 3,64 & 3,32 & 3,53 & 0,35 & 13,20 \\
Oasis & 6,6 & 165 & 25,0 & $x$ & $x$ & $x$ & $x$ & $x$ \\
\hline Total & 421,56 & 18128 & 43,0 & 2,87 & 1,71 & 4,41 & 1,04 & 16,14 \\
\hline
\end{tabular}

Nota: $\mathrm{VU}=$ vias urbanizadas; Narv= número de árvores; $\mathrm{LC}=$ largura média da calçada; Harv= Altura média das árvores; Hbif= altura média de bifurcação das árvores; $\mathrm{DAP}=$ diâmetro médio à altura do peito; $x=$ parâmetro não avaliado.

Paiva et al. (2010) afirmam que o índice de árvore por quilômetro ideal é de 100 árvores, considerando a ocorrência de pelo menos uma árvore na frente de cada residência, estimando-se uma testada média de terrenos urbanos como sendo $10 \mathrm{~m}$. Seguindo o mesmo raciocínio de Paiva et al. (2010), pode-se concluir que na regional Guapiranga e Sabaúna o 
número é bem inferior, já que a cada 100 casas, apenas 7 apresentam árvores em suas calçadas.

A área livre do canteiro foi em média de $1,71 \mathrm{~m}^{2}$, demonstrando que para a média a área livre do canteiro permite o bom desenvolvimento do sistema radicular da arborização. Entretanto, as regionais "Belas Artes e Corumbá", "Ivoty", "Mosteiro" e "Praia dos Sonhos" não atingiram área suficiente para o desenvolvimento pleno da arborização. Biondi e Althaus (2005) afirmam que a área livre de pavimentação do canteiro deve ser de no mínimo $1 \mathrm{~m}^{2}$ e exaltam também a necessidade de que as áreas permeáveis no entorno do tronco sejam proporcionais ao porte da árvore.

Bobrowski, Biondi e Baggenstoss (2009) ressaltam que as áreas permeáveis no entorno das árvores devem ter uma extensão tão maior quanto possível para que haja o crescimento efetivo da arborização, evitando gastos com substituições e reparação dos danos causados em função do seu desenvolvimento.

Biondi e Lima Neto (2011) enfatizam que se as áreas de canteiro forem muito pequenas, não permitem a infiltração de água causando o afloramento das raízes, sendo assim, quanto maior a área do canteiro melhor o desenvolvimento das árvores e a compatibilidade com a calçada.

Cerca de $28,5 \%$ dos indivíduos arbóreos não apresentaram canteiro ou tiveram seu canteiro totalmente pavimentado, sendo este um fator determinante na qualidade das árvores e da estrutura urbana. O valor encontrado no município é muito superior ao encontrado em Piracicaba - SP, onde as áreas de canteiro totalmente pavimentadas atingiram $8 \%$ dos indivíduos amostrados (VOLPE-FILIK; SILVA; LIMA, 2007).

Quanto à distribuição dendrométrica dos indivíduos arbóreos avaliados, a média de DAP foi de $16,14 \mathrm{~cm}$ e a altura média foi de $4,41 \mathrm{~m}$, demonstrando que os indivíduos implantados na arborização são jovens e/ou de pequeno a médio porte, diminuindo a probabilidade de apresentarem raízes agressivas e que interfiram na qualidade das calçadas.

Resultados similares foram encontrados na arborização viária de Araçoiaba da Serra $\mathrm{SP}$, onde aproximadamente $60 \%$ dos indivíduos apresentavam menos de $5 \mathrm{~m}$ de altura e aproximadamente $80 \%$ apresentava DAP entre 5 e $35 \mathrm{~cm}$ (GRACIANO-SILVA; CARDOSOLEITE; TONELLO, 2014).

Pode-se observar uma correlação positiva moderada entre o porte das árvores (altura e DAP) e a porcentagem de raízes superficiais (PRS), demonstrando que em aproximadamente $60 \%$ dos casos o grande porte da arborização ocasionou afloramento das raízes na superfície (Figura 3). 


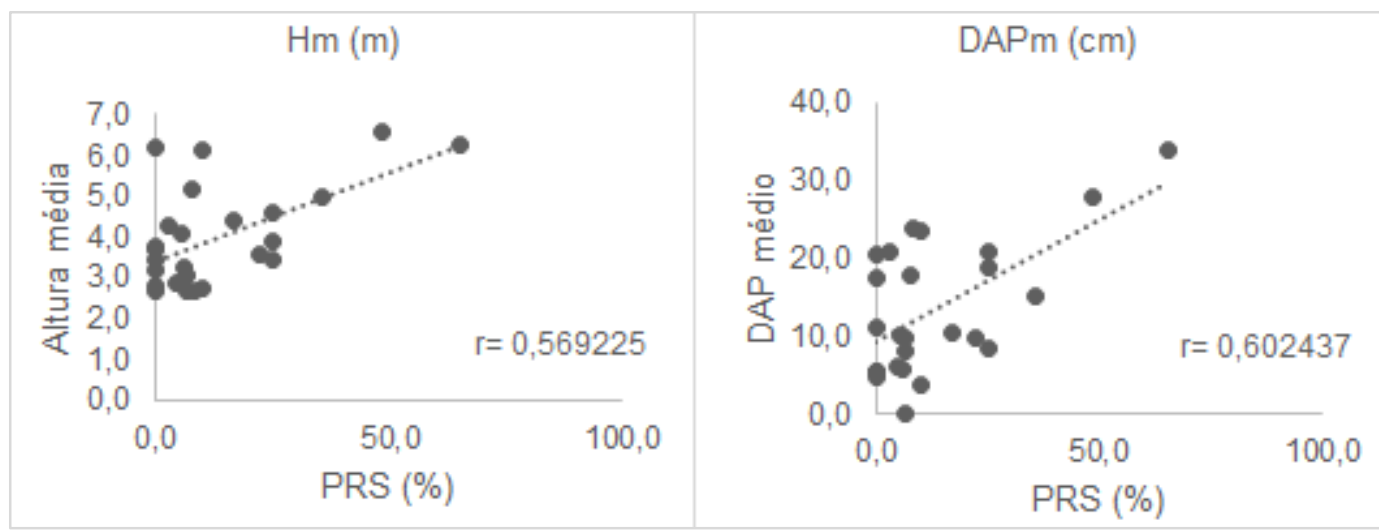

Figura 3. Correlação linear entre DAP $(\mathrm{cm})$ e Porcentagem de Raiz Superficial (PRS - \%) e altura média $(\mathrm{Hm})$ e Porcentagem de Raiz Superficial (PRS - \%)

Figure 3. Linear Correlation between DAP $(\mathrm{cm})$ and Percentage of Surface Root (PRS - \%) and mean height $(\mathrm{Hm})$ and Percentage of Surface Root (PRS -\%)

O mesmo resultado foi encontrado no município de Cosmópolis - SP, onde Paiva (2009) constatou uma correlação linear positiva entre o DAP das árvores e os danos causados às calçadas, concluindo que espécies de maior porte são as que provocam danos mais significativos.

Muitos autores afirmam que as árvores destinadas à arborização urbana, principalmente de calçadas, devem apresentar altura de bifurcação superior a 1,80 m, de modo que os galhos não interfiram no trânsito de pedestres (MARTINI; GASPAR; BIONDI, 2014) e de pessoas com deficiência visual.

Os resultados encontrados demonstraram que a maioria dos indivíduos implantados $(76,8 \%)$ não apresentou altura de bifurcação adequada (maior que 1,8 m) para que não cause interferência no deslocamento dos pedestres (Figura 4).

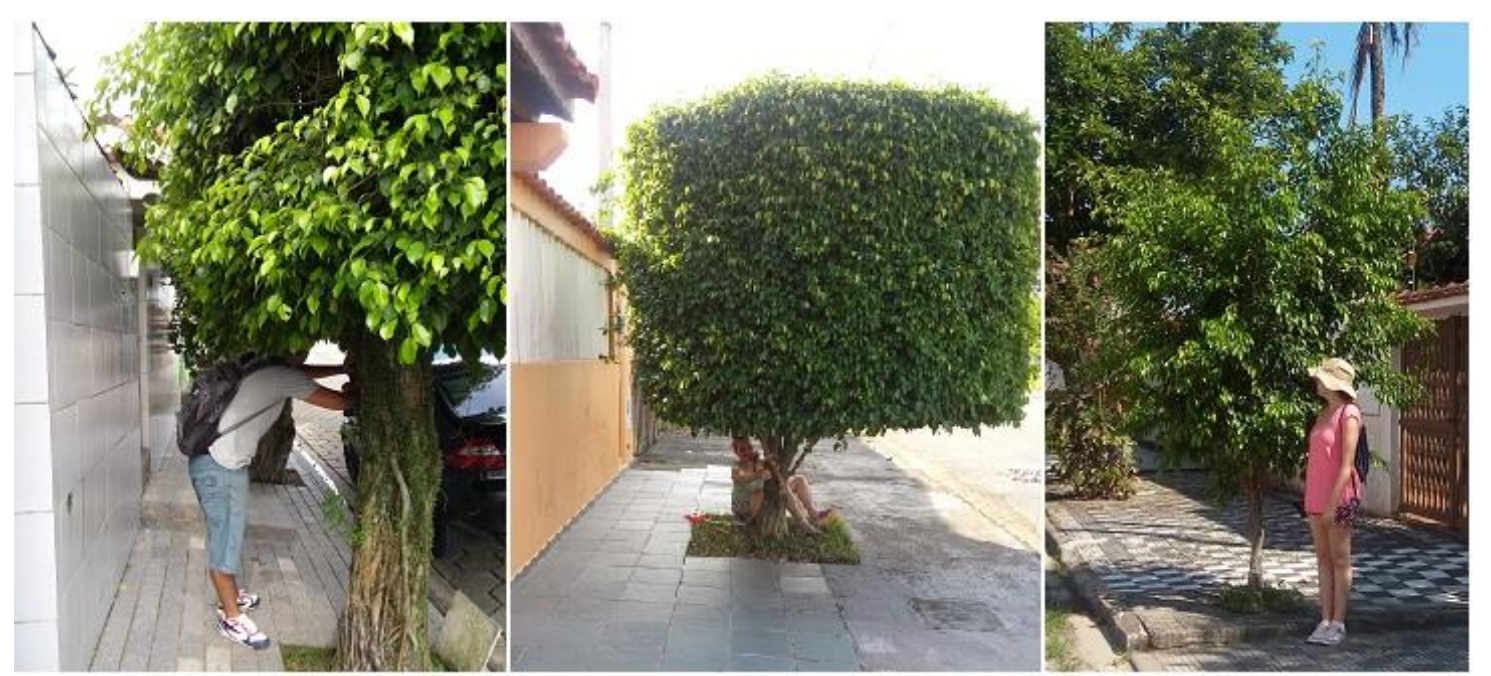

Figura 4. Árvores com bifurcação abaixo de 1,8m encontradas em Itanhaém - SP, dificultando a circulação de pedestres

Figure 4. Trees with bifurcation below $1.8 \mathrm{~m}$ found in Itanhaém - SP, hindering the circulation of pedestrians 
Lima Neto et al. (2010) afirmam que a altura de bifurcação pode representar um problema para o trânsito de pedestres, principalmente para os que apresentam mobilidade reduzida, quando a mesma apresenta altura de bifurcação inferior à recomendada (1,8 m).

O município apresentou $2.417 \mathrm{~km}^{2}$ de área de calçadas, com largura média de 2,87 m, demonstrando que em média é possível aplicar métodos que transformem as calçadas em caminhos acessíveis, possibilitando a aplicação das faixas de circulação livre e de serviço, que segundo o plano municipal de acessibilidade de São Paulo (LAMOUNIER, 2015) devem apresentar $1,5 \mathrm{~m}$ e $0,8 \mathrm{~m}$ respectivamente, permitindo a faixa de acesso em alguns casos (Tabela 3).

O município apresentou expressiva heterogeneidade na caracterização do meio físico das regionais, sendo que a largura média das calçadas variou entre 2,02 $\mathrm{m}$ na regional "Praia dos Sonhos" e 3,64 m na regional "Umuarama".

Almeida e Ferreira (2008), afirmam que o ideal é que as calçadas tenham no mínimo 2,5 m de largura, pois quanto maior a largura da calçada melhor será a proteção dos pedestres e a qualidade da vegetação, favorecendo a paisagem urbana e o conforto. Pode-se observar que quase todas as regionais, com planejamento adequado, comportariam largura mínima proposta pelo autor, podendo dispor de faixa de circulação livre na largura recomendável, de $1,5 \mathrm{~m}$, faixa de serviços e faixa de acesso.

Tabela 3. Caracterização da posição média das árvores nas calçadas de Itanhaém-SP

Table 3. Characterization of the average position of the trees in the sidewalks of Itanhaém-SP

\begin{tabular}{lcccc}
\hline Regional & LC $(\mathbf{m})$ & DAC $(\mathbf{m})$ & DAMF $(\mathbf{m})$ & DF $(\mathbf{m})$ \\
\hline Belas Artes e Corumbá & 2,69 & 1,29 & 1,51 & 1,81 \\
Bopiranga & 3,17 & 1,14 & 1,99 & 2,15 \\
Centro & 2,94 & 0,70 & 2,26 & 3,85 \\
Cibratel & 3,06 & 1,10 & 1,93 & 3,94 \\
Giavota & 2,97 & 1,18 & 1,79 & 3,58 \\
Guapiranga e Sabaúna & 2,71 & 1,47 & 1,24 & 3,63 \\
Ivoty & 2,86 & 1,07 & 1,79 & 2,21 \\
Loty & 3,47 & 1,41 & 2,05 & 4,69 \\
Mosteiro & 2,71 & 0,92 & 1,71 & 2,88 \\
Praia dos Sonhos & 2,02 & 0,65 & 1,33 & 3,35 \\
Savoy e Nova Itanhaém & 2,67 & 1,05 & 1,64 & 2,1 \\
Suarão & 2,41 & 1,02 & 1,39 & 3,03 \\
Umuarama & 3,64 & 2,16 & 1,48 & 1,58 \\
\hline Média & 2,87 & 1,17 & 1,70 & 2,98 \\
\hline
\end{tabular}

Nota: $\mathrm{LC}=$ Largura da calçada; $\mathrm{DAC}=$ distância média da árvore à casa; DAMF= distância média da árvore ao meio fio; $\mathrm{DF}=$ Distância da Fiação.

Milano e Dalcin (2000) afirmam que além da largura das calçadas deve-se considerar o recuo das construções para que se possa implantar a arborização de forma mais apropriada. 
Assim, em calçadas com largura menores que 3,0 m, com ou sem recuo predial, recomenda-se o uso de árvores de médio porte, enquanto que em calçadas com mais de 3,0 m de largura e com recuo da edificação de mais de $5,0 \mathrm{~m}$, é possível a utilização de espécies de grande porte.

A distância média do tronco à rede de distribuição de energia elétrica foi de 2,98 m, enquanto que o raio médio da copa foi de $2,20 \mathrm{~m}$, resultando numa distância média de $78 \mathrm{~cm}$ entre a copa e a fiação. Isto demonstra que a distância do limite da copa até a fiação é insuficiente, pois, de acordo com o manual de arborização da COPEL (2016), é recomendada uma distância mínima de 1,0 m entre o limite da copa e a fiação.

Quanto à posição da árvore na calçada, pode-se observar que em média as árvores estão mais próximas das casas $(1,17 \mathrm{~m})$ do que do meio fio $(1,70 \mathrm{~m})$, com exceção das Regionais "Guapiranga e Sabaúna" e "Umuarama", onde as distâncias das casas (1,47 m e $2,16 \mathrm{~m}$, respectivmente) foram maiores que as distâncias do meio fio (1,24 m e 1,48 m, respectivamente).

A posição das árvores possivelmente está ligada à proximidade dos moradores com a vegetação, já que as regiões que apresentam as árvores mais distantes das casas são as que tem maior proximidade com a formação florestal nativa do município.

Porém a proximidade da arborização viária das residências não é a mais adequada já que estas devem estar posicionadas dentro da faixa de serviços e segundo Alvarez e Camisão (2004), a faixa de serviços bem como os elementos urbanos devem se localizar preferivelmente na parte externa da calçada, facilitando sua manutenção.

Os dados da largura média da calçada não são os únicos que condicionam a implantação das faixas de circulação livre e de serviços. A implantação e/ou adequação das faixas de utilização devem se adequar a posição da arborização já implantada, adequando-se também o mobiliário, para que ambos permaneçam inseridos na faixa de serviços. Sendo assim, a proposição apresentada neste estudo indica que, embora não sendo a situação ideal, na maioria das regionais a faixa de circulação de pedestres seja alocada no lado externo das calçadas, dada a posição atual das árvores.

Em média a projeção da faixa de serviços na lateral externa das calçadas (divisa com a guia e o leito carroçável) indicada como melhor localização por Alvarez e Camisão (2004) só é possível de ser aplicada em apenas duas das treze regionais estudadas. Como são considerados o posicionamento médio para as regionais, deve-se priorizar, quando possível, a adequação da faixa de circulação na parte interna da calçada (Figura 5). 


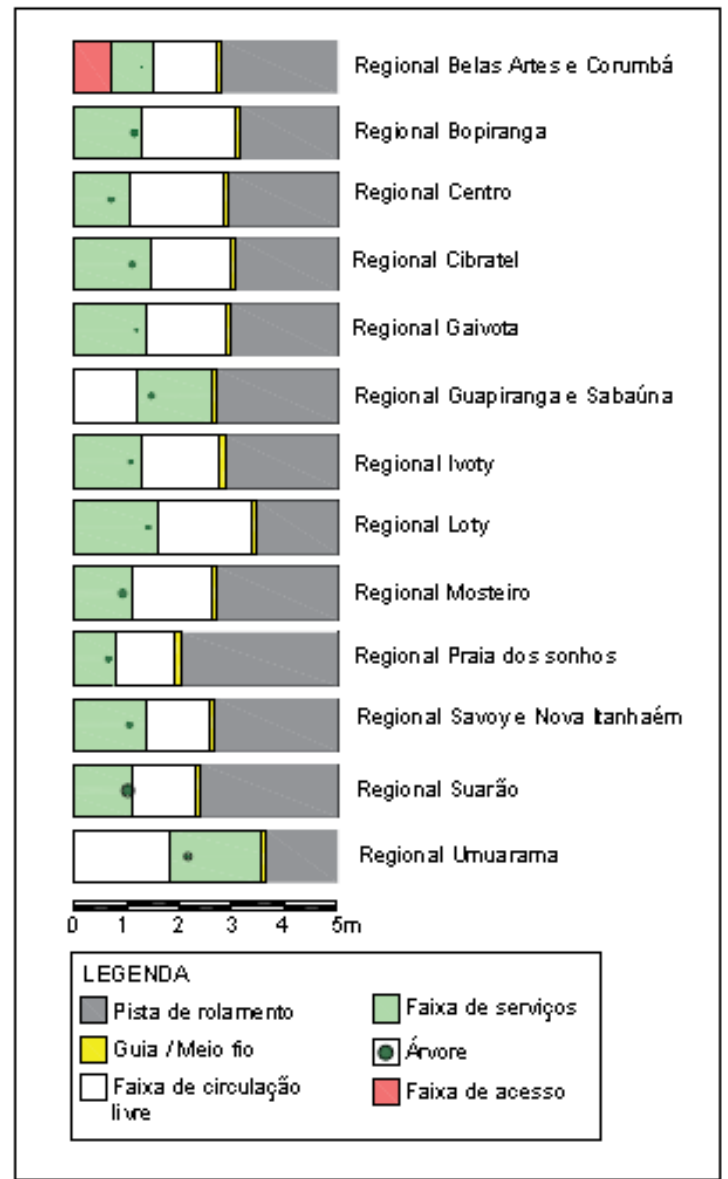

Figura 5. Proposta para localização das faixas de utilização das calçadas das regionais de Itanhaém SP de acordo com a posição média da árvore nas calçadas

Figure 5. Proposal to locate the sidewalks use ranges of the regional of Itanhaém - SP according to the average position of the tree on the sidewalks

A faixa de serviços pode ser implantada somente na regional "Belas Artes", porém, indica-se que a faixa de serviços seja implantada somente nas vias com necessidade de apoio às propriedades, já que a locação desta faixa reduz a largura da faixa de circulação livre à 1,30 $\mathrm{m}$, menor que a largura recomendável (1,50 m).

A regional "Centro", por se tratar de uma região comercial, deveria apresentar a faixa de serviços, porém, considerando o grande fluxo de pessoas na região, deve-se priorizar uma largura mínima de 1,8 m para as calçadas desta região para permitir a circulação simultânea de mais pessoas.

Com base na localização das faixas de utilização e de acordo com a posição do mobiliário árvore, foram definidas as larguras das faixas de cada regional e a compatibilidade de circulação (Tabela 4). 
Tabela 4. Largura das faixas de utilização propostas e tipos de circulação possíveis nas calçadas de Itanhaém - SP

Table 4. Width of the proposed use ranges and possible circulation types in the sidewalks of Itanhaém - SP

\begin{tabular}{|c|c|c|c|c|}
\hline \multirow{2}{*}{ Regional } & \multicolumn{3}{|c|}{ Faixa } & \multirow{2}{*}{ Permite Circulação simultânea } \\
\hline & $\overline{C L}$ & s & A & \\
\hline Belas Artes e Corumbá & 1,3 & 0,8 & 0,7 & \\
\hline Bopiranga & 1,9 & 1,27 & 0 & \\
\hline Centro & 1,9 & 1,04 & 0 & \\
\hline Cibratel & 1.6 & 1,46 & 0 & \\
\hline Gaivota & 1,6 & 1,37 & 0 & \\
\hline Guapiranga e Sabaúna & 1,2 & 1,51 & 0 & \\
\hline Ivoty & 1,6 & 1,26 & 0 & \\
\hline Loty & 1,9 & 1,57 & 0 & \\
\hline Mosteiro & 1,6 & 1,11 & 0 & \\
\hline Praia dos sonhos & 1,2 & 0,82 & 0 & \\
\hline Savoy e Nova Itanhaém & 1,3 & 1,37 & 0 & $G$ \\
\hline Suarão & 1,3 & 1,11 & 0 & $E$ \\
\hline Umuarama & 1,8 & 1,84 & 0 & 5 \\
\hline
\end{tabular}

Pode-se observar que com a projeção das faixas de utilização de acordo com as características das calçadas atuais, as regionais que apresentaram maiores restrições à acessibilidade foram as regionais "Guapiranga e Sabaúna", "Praia dos Sonhos", "Savoy e Nova Itanhaém" e "Suarão". Estas regionais não puderam apresentar a largura mínima recomendável de 1,5 m, mas apresentam a largura mínima aceitável de $1,2 \mathrm{~m}$, permitindo conforto na circulação de cadeirantes ou pessoas com mobilidade reduzida.

A faixa de circulação livre pode ser aplicada em todas as calçadas do município. Ainda que a posição do mobiliário estabelecido não siga um padrão, é possível transpor alguns deles, e em casos em que a transposição não seja possível, deve-se considerar o desenho orgânico da faixa de circulação livre, respeitando a largura mínima aceitável entre os mobiliários, permitindo a passagem de ao menos uma pessoa com mobilidade reduzida.

O planejamento dos novos loteamentos do município, bem como a reforma e adequação das calçadas já estabelecidas, deve respeitar a locação do mobiliário urbano, exclusivo na faixa de serviços, visando atender os requisitos básicos da acessibilidade no território municipal. 


\section{CONCLUSÕES}

A largura média das calçadas de Itanhaém possibilita a aplicabilidade das calçadas acessíveis em todas as regionais, sendo que $77 \%$ apresentam a largura mínima recomendável de $1,5 \mathrm{~m}$, permitindo a circulação confortável de no mínimo uma pessoa com mobilidade reduzida ou um cadeirante.

A arborização implantada apresenta como principais limitações relacionadas à acessibilidade a baixa altura de bifurcação das árvores, demonstrando a necessidade de adequação das mesmas e a implantação de mudas com altura de bifurcação superior a 1,8 m.

Deve-se considerar, principalmente nas calçadas mais estreitas do município, a implantação de indivíduos de pequeno ou médio porte nas calçadas, devido a correlação positiva entre o porte e a probabilidade de afloramento das raízes.

Este estudo demonstra que as calçadas verdes acessíveis são passíveis de serem aplicadas em todas as regionais, preservando a vegetação e oferecendo condições de acesso a todos os cidadãos.

\section{REFERÊNCIAS}

ALMEIDA, R. B.; FERREIRA, O. M. Calçadas ecológicas: construção e benefícios sócioambientais. Universidade Católica de Goiás - Departamento de Engenharia - Engenharia Ambiental. Goiânia: PROPE. PUC, 2008. 28p

ALVAREZ, C. A.; STAPE, J. L.; SENTELHAS, P. C.; GONÇALVES, J. L. M.; SPAROVEK, G. Köppen's climate classification map for Brazil. Meteorologische Zeitschrift, Stuttgart, v. 22, n. 6, p. 711-728, 2013.

ALVAREZ, E.; CAMISÃO, V. Guia operacional de acessibilidade para projetos de desenvolvimento urbano com critérios de desenho universal. Banco Interamericano de Desenvolvimento, Rio de Janeiro, 2004, 47p.

BIONDI, D.; ALTHAUS, M. Árvores de rua de Curitiba: cultivo e manejo. Curitiba: FUPEF, 2005.

BIONDI, D.; LIMA NETO, E. M. Pesquisa em arborização de ruas. Curitiba, O Autor, 150p. 2011.

BOBROWSKI, R.; BIONDI, D.; BAGGENSTOSS, D. Composição de canteiros na arborização de ruas de Curitiba (PR). Revista da Sociedade Brasileira de Arborização Urbana. Piracicaba, v.1, n.1, p.44-61, 2009.

GRACIANO-SILVA, T.; CARDOSO-LEITE, E.; TONELLO, K. C. Inventário da arborização urbana no município de Araçoiaba da Serra, SP. Revista da Sociedade Brasileira de Arborização Urbana, Piracicaba, v. 9, n. 4, p. 151-169, 2014. 
GRISE; M. M.; BIONDI, D.; ARAKI, H. Distribuição Espacial e Cobertura de Vegetação das Tipologias de Áreas Verdes de Curitiba, PR. Floresta e Ambiente, Seropédica, v. 23, n. 4, p. 498-510, 2016.

HAUBRICHT, D. M.; FIORINI, F. A. Percepção ambiental dos moradores do assentamento Vila Rural I do município de Alta Floresta - MT. Revista da Universidade Vale do Rio Verde, Três Corações, v. 12, n. 1, p. 248-256, 2014.

INSTITUTO BRASILEIRO DE GEOGRAFIA E ESTATISTICA - IBGE. Censo 2010. Disponível em: <http://censo2010.ibge.gov.br/noticiascenso?view=noticia\&id=3\&idnoticia $=1766$ \&busca $=1$ \& $\mathrm{t}=$ censo-2010-populacao-brasil-190- 732-694-pessoas>. Acesso em: 07 de jan. 2014.

INSTITUTO DE PESQUISAS TECNOLÓGICAS DO ESTADO DE SÃO PAULO - IPT. PREFEITURA MUNICIPAL DE ITANHAÉM - PMI. Atlas Ambiental do município de Itanhaém - 2012. São Paulo: Imprensa Oficial, 2012, 92p.

KEPPE JUNIOR, C L. G. Formulação de um indicador de acessibilidade das calçadas e travessias. Revista Pós, São Paulo, v. 15, n. 24, 2008.

LAMOUNIER, L. P. Acessibilidade em calçadas. Consultoria Legislativa, Brasília, 2015.

LICHT, C. B. Turismo e Inclusão Social: um estudo de caso sobre a estrutura da cidade de Porto Alegre para receber turistas com deficiência ou mobilidade reduzida. Fólio-Revista Científica Digital-Jornalismo, Publicidade e Turismo, Porto Alegre, v. 1, n. 1, p. 112-131, 2015.

LIMA NETO, E. M.; BARDELLI-DA-SILVA, M. Y.; SILVA, A. R.; BIONDI, D. Arborização de ruas e acessibilidade no bairro Centro de Curitiba-PR. Revista da Sociedade Brasileira de Arborização Urbana, Piracicaba, v.5, n.4, p. 40-56, 2010.

MARTINI, A.; GASPAR, R. G. B.; BIONDI, D. diagnóstico da implantação da arborização de ruas no bairro Santa Quitéria, Curitiba - PR. Revista da Sociedade Brasileira de Arborização Urbana. Piracicaba - SP, v. 9, n. 2, p. 148-167, 2014.

PAIVA, A. V.; LIMA, A. B. M.; CARVALHO, A.; JUNIOR, A.; GOMES, A.; MELO, C. S.; FARIAS, C. O.; REIS, C.; BEZERRA, C.; JUNIOR, E. A. S.; MACEDO, E.; LIMA, E. S.; SOBRINHO, F.; SILVA, F. M.; BONFIM, J. C.; S. JUNIOR, L.; CORREA, M.; DUMONT, M. L.; ISAAC JUNIOR, M. A.; PANTOJA, N. V.; DAVILA, R. M.; GABRIEL, R.; SILVA, R. A.; CUNHA, R. M.; OLIVEIRA, R. S.; DIAS R.; NICHELI, S. P.; COSTA, S.; SOUZA, T. C.; PEREIRA, T. F.; CASTELO, Z.; FERRARI, Z. S. Inventário e diagnóstico da arborização urbana viária de Rio Branco, AC. Revista da Sociedade Brasileira de Arborização Urbana, Piracicaba, v. 5, n. 1, p. 144 - 159 , 2010.

PAIVA, A. V. Aspectos da arborização urbana do Centro de Cosmópolis -SP. Revista da Sociedade Brasileira de Arborização Urbana, Piracicaba, v. 4, n. 4, p. 17-31, 2009.

PEREIRA, F. C.; BARBOSA, A. C. L.; PEREIRA JÚNIOR, C. Dos velhos aos novos desafios à acessibilidade em consonância com desenho urbano. Revista Includere, Mossoró, v. 2, n. 1, p. 63-66, 2016.

RIBEIRO, V. C.; VARELA, S. Acessibilidade nas calçadas urbanas de uma cidade da Serra Catarinense. Revista GepesVida, Lages, v. 1, n. 2, 2015. 
RUOSO, D. A percepção climática da população urbana de Santa Cruz do Sul/RS. Revista RA'E GA, Curitiba, v. 25, n. 1, p. 64-91, 2012.

SOARES, A. M. J.; ALVES, R. L.; TARGINO, E. N. M. A. Acessibilidade na arborização urbana: percepção de deficientes visuais sobre a mobilidade em espaços públicos arborizados. Revista da Sociedade Brasileira de Arborização Urbana, Piracicaba, v. 12, n. 3, p. 51-65, 2017.

UGEDA JUNIOR, J. C. Planejamento da paisagem e planejamento urbano: reflexões sobre a urbanização brasileira. Revista Mato-Grossense de Geografia, Cuiabá, v. 17, n. 1, p. 101116, 2014.

VOLPE-FILIK, A.; SILVA, L. F.; LIMA, A. M. L. P. Avaliação da arborização de ruas do bairro São Dimas na cidade de Piracicaba/SP através de parâmetros qualitativos. Revista da Sociedade Brasileira da Arborização Urbana, Piracicaba, v. 2, n. 1, 2007.

ZHU, P.; ZHANG, Y. Demand for urban forests in United States cities. Landscape and Urban Planning. Amsterdam, v.84, p.293-300, 2008. 